\title{
Effect of $\beta$-agonist on the dexamethasone-induced expression of aromatase by the human monocyte cells
}

\author{
Masatada Watanabe', Shuji Ohno ${ }^{2}$ and Hiroshi Wachi ${ }^{1}$ \\ ${ }^{1}$ Laboratory of Tissue Regeneration, Hoshi University School of Pharmacy and Pharmaceutical Sciences, \\ Shinagawa, Tokyo, Japan \\ ${ }^{2}$ Division of Research for Pharmacy Students Education, Hoshi University, Shinagawa, Tokyo, Japan
}

Correspondence

should be addressed

to M Watanabe

Email

masatada@hoshi.ac.jp

\begin{abstract}
Emerging evidence suggests that sex steroids are important for human skin health. In particular, estrogen improves skin thickness, elasticity and moisture of older women. The major source of circulating estrogen is the ovary; however, local estrogen synthesis and secretion have important roles in, for example, bone metabolism and breast cancer development. We hypothesized that infiltrated peripheral monocytes are one of the sources of estrogen in skin tissues. We also hypothesized that, during atopic dermatitis under stress, a decline in the hypothalamus-pituitary-adrenal axis (HPA) and facilitation of the (hypothalamus)-sympathetic-adrenomedullary system (SAM) attenuates estrogen secretion from monocytes. Based on this hypothesis, we tested aromatase expression in the human peripheral monocyte-derived cell line THP-1 in response to the synthetic glucocorticoid dexamethasone (Dex), the synthetic $\beta$-agonist isoproterenol (Iso) and the $\beta$-antagonist propranolol (Pro). Dex mimics glucocorticoid secreted during excitation of the HPA, and Iso mimics catecholamine secreted during excitation of the SAM. We found that aromatase activity and the CYP19A1 gene transcript were both upregulated in THP-1 cells in the presence of Dex. Addition of Iso induced their downregulation and further addition of Pro rescued aromatase expression. These results may suggest that attenuation of estrogen secretion from peripheral monocytes could be a part of the pathology of stress-caused deterioration of atopic dermatitis. Further examination using an in vitro human skin model including THP-1 cells might be a valuable tool for investigating the therapeutic efficacy and mechanism of estrogen treatment for skin health.
\end{abstract}

\author{
Key Words \\ - $\beta$-agonist \\ - aromatase \\ - atopic dermatitis \\ - monocyte \\ - estrogen
}

\section{Introduction}

Sex steroids are important for the maintenance of healthy skin. Based on studies on older women, sex steroids in skin regulate the collagen content and the synthesis of hyaluronic acid (1). Estrogen-conjugated cream applied to the face of women aged 52-70 years improved their skin thickness (epidermis + dermis) (2). Oral application of an estrogen-conjugated tablet in postmenopausal
(C) 2017 The authors

http.//Ww.endocrineconnections.org DOI: 10.1530/EC-16-0099 women improved skin elasticity, moisture and thickness (3). Aromatase inhibitors (e.g. exemestane) employed as part of breast cancer therapy cause vasculitis in skin tissues with cutaneous eruptions and palpable purpura as side effects (4). These reports suggest that sex steroids, especially estrogen, are important for the maintenance of skin moisture and elasticity. 
In this study, we investigated the possibility of in situ expression of aromatase, the last step and the ratelimiting enzyme in estrogen biosynthesis, in human skin tissues. Several previous reports have described the expression of aromatase in human skin tissues (5), and aromatase expression has been reported in human hair follicles and sebaceous glands (6). The dermis expresses aromatase, and there is a positive correlation between estrogen concentration and the number of transcripts of the CYP19A1 gene in human skin tissues (7).

In vitro-cultured human skin fibroblast cells have been reported to express aromatase $(8,9)$. Aromatase activity was induced in human skin fibroblasts by dexamethasone (Dex), a cAMP analog, insulin and IGF-I in the presence of serum (8). During expression of the CYP19A1 gene in human fibroblasts, of the multiple exons I in the human CYP19A1 gene (Fig. 1A), exon I.4 (exon 1b) was mainly selected as the 5'-UTR of the CYP19A1 gene transcript (9). This finding suggests that promoter I.4, 5'-upstream region of exon I.4, is activated in human skin fibroblasts.

In addition to fibroblasts, we propose that peripheral monocytes and monocyte-derived cells are also potentially estrogen-secreting cells. Human skin tissue includes Langerhans cells, which are composed of a variety of monocyte-derived dendritic or macrophage cells. Monocytes infiltrate into allergic skin tissue and differentiate into anti-inflammatory macrophages (10). These features suggest that monocytes and monocyte- derived cells play physiologically and pathologically important roles in human skin tissues. From the viewpoint of estrogen production, aromatase expression has been reported in monocytes and macrophages $(11,12)$. Based on the importance of monocytes and monocyte-derived cells in skin tissue and the aromatase expression in these cells, it could be proposed that monocytes and monocyte-derived cells act to reduce inflammation during dermatitis, and, at the stage of healing, these cells secrete estrogen to assist the recovery of healthy skin tissue.

THP-1, a human peripheral monocyte-derived cell line (13), has been used for research into monocytes, macrophages and Langerhans cells in skin tissue (14, $15,16)$. Aromatase has been reported to be expressed in THP-1 cells and synthetic glucocorticoid Dex and phorbol myristate acetate (PMA) induce the expression of aromatase in THP-1 cells (17). Based on these data, we used an in vitro THP-1 culture system to investigate the expression of aromatase in human skin monocytes.

We observed a relationship between atopic dermatitis and stress in human skin tissue. Recent studies also suggest a relationship between stress and atopic dermatitis. In an investigation of the stress response, which was determined by the measurement of salivary cortisol concentration and plasma catecholamine concentration before and after standardized laboratory stress exposure, subjects with atopic dermatitis showed a low increase in cortisol
A

Multiple exons I in human CYP19A1 gene

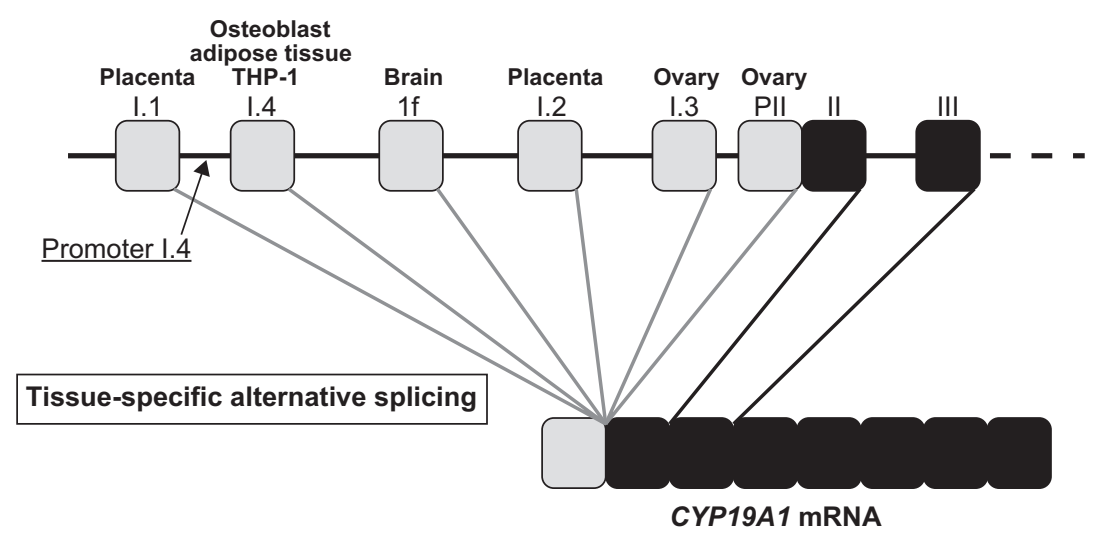

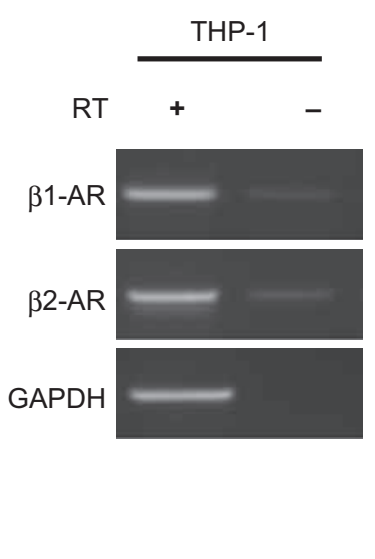

Figure 1

(A) Scheme of the multiple exons I in the human CYP19A1 gene- and tissue-specific alternative splicing. Multiple exons I (gray boxes) and peptide-coding exons (black boxes) are alternatively spliced in a tissue-specific fashion. Well-known tissues in which each exon is specifically selected are shown above the names of the exons I. The arrow indicates the position of promoter I.4. (B) RT-PCR analysis of the expression of $\beta$-adrenergic receptors in THP-1 cells. Expression of gene transcripts of the $\beta 1$-adrenergic receptor ( $\beta 1$-AR) and the $\beta 2$-AR were examined by RT-PCR using specific primers for each receptor. DNA sequencing analysis confirmed the identity between PCR products and $\beta$-ARs. GAPDH gene transcripts were examined as internal controls. $\mathrm{RT}+$ and RT- indicate the presence or absence of reverse transcriptase during the reaction of reverse transcription.

http://www.endocrineconnections.org DOI: 10.1530/EC-16-0099 (c) 2017 The authors Published by Bioscientifica Ltd
This work is licensed under a Creative Commons Attribution-NonCommercial-NoDerivatives 4.0 International License. 
concentration and a marked increase in catecholamine concentration compared to healthy subjects (18). An increase in salivary cortisol concentration reflects the response of the hypothalamus-pituitary-adrenal axis (HPA) to stress, whereas an increase in plasma catecholamine concentration reflects the response of the (hypothalamus)-sympathetic-adrenomedullary system (SAM) to stress. Therefore, the results of standardized laboratory stress tests suggest that the function of the HPA declined and the function of the SAM increased in subjects with atopic dermatitis, implying that there is a low cortisol concentration and a high catecholamine concentration in the skin tissues of patients with atopic dermatitis. A decline in cortisol concentration in skin tissue would make it impossible to suppress excess immunoreactions. Another effect of a decline in cortisol levels in skin tissue would be a decrease in glucocorticoid-dependent estrogen secretion from fibroblasts and monocytes, which would delay the repair of damaged skin tissue. These effects would exacerbate the damage to skin tissues caused by atopic dermatitis.

On the other hand, the effect of increased catecholamine levels by excitation of the SAM in the skin tissue of subjects with atopic dermatitis is unknown.

Based on these observations, as a first trial to investigate the effect of catecholamines on skin tissue, we investigated the effect of a catecholamine upon aromatase expression in cultured human monocytes. The synthetic $\beta$-agonist isoproterenol (Iso) and Dex were used as substitutes for catecholamine and cortisol, respectively. An in vitro culture system of THP-1 cells was used to mimic the monocytes of human skin tissue.

\section{Materials and methods}

\section{Chemicals}

Dex was from Wako Pure Chemical Industries. Iso and propranolol (Pro) were from Sigma-Aldrich.

\section{Cells}

THP-1 cells were obtained from the Cell Resource Center for Biomedical Research, Institute of Development, Aging and Cancer, Tohoku University (Sendai, Japan). The cells were cultured in RPMI-1640 (Wako Pure Chemical Industries) supplemented with $10 \%$ fetal bovine serum, penicillin and streptomycin at $37^{\circ} \mathrm{C}$ in an atmosphere of $5 \% \mathrm{CO}_{2}$.

$$
\begin{aligned}
& \text { http://www.endocrineconnections.org } \\
& \text { DOI: 10.1530/EC-16-0099 }
\end{aligned}
$$

\section{CYP19A1 enzyme activity assay (aromatase assay)}

CYP19A1 enzyme activity assays were performed based on a previous publication (19). THP-1 cells were incubated overnight in serum-free medium containing various combinations of Dex, Iso and Pro. The medium was then changed to serum-free medium containing $30 \mathrm{pmol}$ $\left[1 \beta-{ }^{3} \mathrm{H}\right]$ androstenedione (NET926: Perkin Elmer). After incubation at $37^{\circ} \mathrm{C}$ for $3 \mathrm{~h}$, the medium was mixed with $30 \%$ trichloroacetic acid. After centrifugation, the upper aqueous phase was mixed with DCC $(5 \%(\mathrm{w} / \mathrm{v})$ charcoal, $0.5 \%(\mathrm{w} / \mathrm{v})$ dextran). After centrifugation, the supernatant was mixed with ACS II aqueous counting scintillant (GE Healthcare). The count of $\left[{ }^{3} \mathrm{H}\right] \mathrm{H}_{2} \mathrm{O}$ that was released during aromatization of the $\left[1 \beta-{ }^{3} \mathrm{H}\right]$ androstenedione was measured. The amount of protein in the cells was measured using a BCA protein assay kit (Life Technologies) after protein extraction with $0.1 \%$ SDS. The $\left[{ }^{3} \mathrm{H}\right] \mathrm{H}_{2} \mathrm{O}$ count was normalized by the amount of protein. Experiments were performed in triplicate $(n=3)$.

\section{Reverse transcription and polymerase chain reaction (RT-PCR)}

Cells were incubated overnight in serum-free media with various combinations of Dex, Iso and Pro. Then, total RNA was extracted with the TRI reagent (Molecular Research Center, Inc., Cincinnati, OH, USA). Reverse transcription (RT) was performed using the iScript cDNA Synthesis kit (Bio-Rad). Polymerase chain reactions (PCR) were performed using the GoTaq Green Master Mix (Promega) and specific primers synthesized by Eurofins Genomics (Tokyo, Japan). Specific forward (F) and reverse (R) primers for the gene transcript of human glyceraldehyde 3-phosphate dehydrogenase (GAPDH, as an internal control) were hGAPDH-F (5'-CGGAGTCAACGGATTTGGTCGTAT-3') and hGAPDH-R (5'-AGCCTTCTCCATGGTGGTGAAGAC-3'). Specific primers for the gene transcript of human $\beta 1$-adrenergic receptor $(\beta 1-\mathrm{AR})$ were hADRB1-F (5'-CTGCTACAACGACCCCAAGT-3') and hADRB1-R (5'-CTTCTTCACCTGCTTCTGGG-3'). Specific primers for the gene transcript of human $\beta 2$-adrenergic receptor $(\beta 2$ AR) were hBeta2AR-F (5'-CCTTATCTACTGCCGGAGCC-3') and hBeta2AR-R (5'-TCCTCCCTTGTGAATCAATG-3'). The PCR reactions were as follows. For GAPDH, nineteen 30-s cycles of 94,63 and $72^{\circ} \mathrm{C}$ were used and the expected PCR product size is 307 base pairs (bp). For $\beta 1-A R$, thirty 30 -s cycles of 94,62 and $72^{\circ} \mathrm{C}$ were used and the expected PCR product size is $148 \mathrm{bp}$. For $\beta 2$-AR, thirty-five 30 -s This work is licensed under a Creative Commons
Attribution-NonCommercial-NoDerivatives 4.0 International License. 
cycles of 94,60 and $72^{\circ} \mathrm{C}$ were used and the expected PCR product size is $245 \mathrm{bp}$. DNA sequencing was performed by Macrogen Japan, Corp. (Tokyo, Japan).

\section{Quantitative RT-PCR}

Quantitative RT-PCR was performed using complementary DNA (cDNA) synthesized for RT-PCR, the LightCycler 480 system (Roche Diagnostics) and SsoFast Supermix (Bio-Rad). The primers used were as follows. For the gene transcript of human GAPDH, qhGAPDH-F (5'-TCCACTGGCGTCTTCACC-3') and qhGAPDH-R (5'-GGCAGAGATGATGACCCTTTT-3') were used. For the coding region of the human CYP19A1 gene transcript, C19-Real-F (5'-CAAACCCAATGAATTTACTCTTGA-3') and C19-Real-R (5'-ACCATGGCGATGTACTTTCC-3') were used. For the exon I.4-harboring human CYP19A1 gene transcript, 19-I.4-F (5'-GTGATGTGATGGGAAACTGG-3') and 19-II-R (5'-GTGATGTGATGGGAAACTGG-3') and 19-II-R (5'-TCAGAGGGGGCAATTTAGAG-3') were used. Enzyme activation was performed at $95^{\circ} \mathrm{C}$ for $30 \mathrm{~s}$, denaturation/annealing/extension was 45 cycles of $95^{\circ} \mathrm{C}$ for $5 \mathrm{~s}, 60^{\circ} \mathrm{C}$ for $20 \mathrm{~s}$ and the melting curve was a continuous increase in temperature from $65^{\circ} \mathrm{C}$ to $95^{\circ} \mathrm{C}$; cooling was performed at $50^{\circ} \mathrm{C}$. Experiments were performed in triplicate $(n=3)$.

\section{Statistics}

Statistical analyses were conducted using GraphPad Prism 5 (GraphPad Software). One-way analyses of variance (ANOVA) followed by Tukey's post hoc test were used to determine the significance between experimental data. $P<0.05$ was considered as statistically significant.

\section{Results}

\section{Expression of $\beta$-adrenergic receptors in THP-1 cells}

To examine the expression of $\beta$-adrenergic receptors $(\beta$-AR) in THP-1 cells, we performed RT-PCR using primers specific for human $\beta 1-A R$ and $\beta 2-A R$ (Fig. 1B). Sequence analysis of the PCR products confirmed amplification of the correct PCR products. Gene transcripts of $\beta 1-A R$ and $\beta 2$-AR were expressed in the THP-1 cell line. This result is consistent with that of a previous study in which the expression of $\beta 1$-AR and $\beta 2$-AR proteins was confirmed in THP-1 cells by immunoblotting (20). (c) 2017 The authors Published by Bioscientifica Ltd

\section{$\beta$-Agonist downregulates aromatase activity in THP-1 cells}

To examine if $\beta$-AR signaling pathways affect the expression of aromatase activity in THP-1 cells, we tested the effect of the $\beta$-agonist Iso and the $\beta$-antagonist Pro on the level of aromatase enzymatic activity in this cell line.

As shown in Fig. 2A, Dex-induced aromatase activity was significantly downregulated in the presence of Iso. Addition of Pro rescued the aromatase activity that was downregulated by Iso. These results suggested that $\beta$-ARs are active in human monocyte-derived THP- 1 cells and that a $\beta$-AR signaling pathway downregulates the expression of aromatase in this cell line.

\section{$\beta$-Agonist downregulates the expression of CYP19A1 gene transcripts in THP-1 cells}

To examine if a $\beta$-AR signaling pathway affects aromatase at the level of CYP19A1 gene expression, we tested the effect of Iso and Pro on expression of the CYP19A1 gene transcript by quantitative RT-PCR using primers corresponding to the coding region of CYP19A1 mRNA. As shown in Fig. 2B, Iso significantly downregulated Dex-induced expression of the CYP19A1 gene transcript starting from a concentration as low as $0.5 \mu \mathrm{M}$. Addition of Pro together with Iso prevented Iso-induced downregulation of the CYP19A1 gene transcript. These results suggested that a $\beta$-AR signaling pathway affects aromatase expression at the level of CYP19A1 gene transcription.

\section{Exon I.4-harboring CYP19A1 gene transcript expression is affected by a $\beta$-agonist and antagonist in THP-1 cells}

Exon I.4 is the common $5^{\prime}$-UTR of CYP19A1 gene transcripts in osteoblasts and THP-1 cells. We thus tested if the Dex-induced expression of exon I.4-harboring CYP19A1 gene transcripts might be affected by Iso and Pro by quantitative RT-PCR using primers corresponding to exon I.4 and the coding exon II. As shown in Fig. 2C, expression of exon I.4-harboring CYP19A1 gene transcripts was affected by Iso and Pro in a similar manner to the coding region (Fig. 2B), suggesting that the promoter I.4, which is the $5^{\prime}$ region of exon I.4, is one of the main targets of the $\beta$-AR signaling pathway that induces CYP19A1 gene expression. http://www.endocrineconnections.org DOI: 10.1530/EC-16-0099 
A

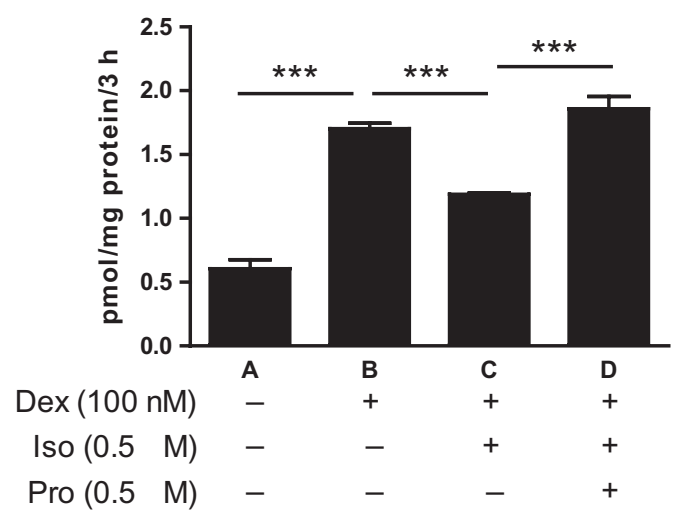

B

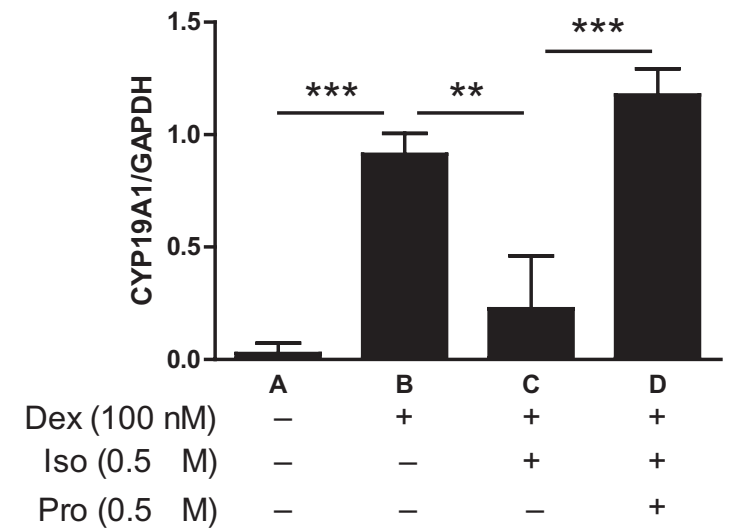

C
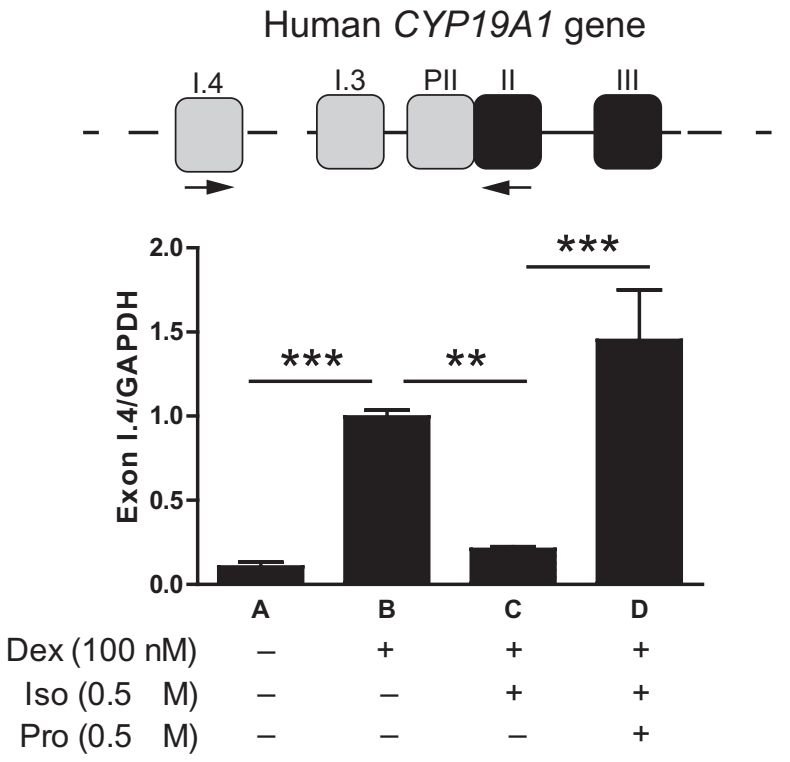

\section{Figure 2}

(A) Isoproterenol downregulates aromatase activity, and propranolol rescues this downregulated aromatase activity in THP-1 cells. Aromatase enzyme activities were measured as described in 'Materials and methods' section after overnight treatment of THP-1 cells with the indicated combinations of dexamethasone (Dex), isoproterenol (Iso) and propranolol (Pro). (B) Isoproterenol downregulates dexamethasoneinduced expression of CYP19A1 gene transcription in THP-1 cells, and

\section{Discussion}

Two physical responses to stress are well described. One response is the HPA, which evokes the secretion of glucocorticoid. In response to glucocorticoid, gluconeogenesis is accelerated. The second response was observed in the SAM system, in which increased secretion of adrenaline and noradrenaline accelerates heart beat and increases blood pressure. The combination of HPA and SAM increases the blood glucose generated by gluconeogenesis and the efficiency of the body circulation for quick fight-or-flight reaction.

On the other hand, HPA and SAM can have unfavorable effects. An increase in the circulating adrenaline concentration lowers peripheral and dermal circulation by contraction of peripheral blood vessels, whereas an increase in the circulating glucocorticoid concentration suppresses the immune system. Consequently, longterm stress could make the body vulnerable to atopic dermatitis, in other words, could result in an atopic disposition. Thus, even when the HPA and the SAM are functioning in a proper manner, they could be a cause of atopic dermatitis under stress.

In this study on whether a decline in the HPA and excitation of the SAM cause the deterioration of dermatitis, we assessed the effect of substances that mimics the HPA and the SAM upon cells in human dermal tissues that secrete a beneficial substance. Specifically, we examined estrogen secretion from peripheral monocytes, which infiltrate into skin tissue and secrete a number of cytokines and low-molecular-weight substances, such as estrogen $(21,22)$. The beneficial role of estrogen in skin tissue is well recognized $(2,3)$.

As a model of human peripheral monocytes, we used the human peripheral monocyte-derived cell line, THP-1 (13). Expression of aromatase in THP-1 cells has been reported (17). $\beta 1$ - and $\beta 2$-adrenergic receptors are expressed in THP-1 cells, and this cell line responds to the $\beta$-agonist isoproterenol $(20,23,24)$.

We confirmed the expression of $\beta 1$ - and $\beta 2$-adrenergic receptors $(\beta 1-, \beta 2-\mathrm{AR})$ in our batch of THP-1 cells using

propranolol rescues this downregulated CYP19A1 expression. (C) Dexamethasone-induced expression of an exon 1.4-harboring CYP19A1 gene transcript is affected by isoproterenol and propranolol. Quantitative RT-PCR was performed using primers that correspond to the coding region (B) or exon II and exon I.4 (C; indicated by arrows) of the CYP19A1 gene transcript after overnight treatment of THP-1 cells with the indicated combinations of Dex, Iso and Pro. These experiments were performed in triplicate $(n=3)$. Statistical significance was analyzed using one-way ANOVA and Tukey's post hoc test. $P<0.01$ is indicated as **, $P<0.001$ is indicated as $* * *$. 
RT-PCR (Fig. 1B). Aromatase enzyme activity (Fig. 2A) and the CYP19A1 gene transcript (Fig. 2B) were induced by Dex, which mimics glucocorticoid secreted during HPA excitation. Among the multiple exons I in the CYP19A1 gene (Fig. 1A), activation of promoter I.4 was confirmed (Fig. 2C). However, the co-presence of Iso, which mimics catecholamine secreted during SAM excitation, downregulated these effects of Dex, whereas addition of the synthetic $\beta$-antagonist Pro rescued the downregulation induced by Iso. Dex dependency of aromatase expression and its downregulation by Iso suggest that a decline in the HPA and excitation of the SAM suppressed the expression of aromatase in peripheral monocytes. These results also suggest the presence of suppressive crosstalk between the glucocorticoid signaling pathway and the $\beta$-AR signaling pathway. A well-known intracellular second messenger in the $\beta$-AR signaling pathway is an increase in cyclic AMP (cAMP) concentration ([cAMP]i). An increase in [CAMP]i and activation of protein kinase A (PKA) might interfere with the action of ligand-occupied glucocorticoid receptor (GR). To better understand the mechanism of catecholamine effects on skin tissue, further examination of this or other intracellular crosstalk is necessary. In our previous study using a human osteoblastic cell line, aromatase expression was synergistically upregulated in the presence of both Dex and the [cAMP]i inducer forskolin or prostaglandin $\mathrm{E}_{2}(25,26)$. The promoter $\mathrm{I} .4$ was also synergistically activated. These opposite phenomena in the THP-1 and osteoblastic cell lines might suggest a difference in intracellular signaling mechanisms between cells of hematopoietic stem cell origin and cells of mesenchymal stem cell origin. This difference might provide a basis for new tissue-specific or cell-specific pharmacotherapeutic utilization of glucocorticoids, $\beta$-agonists and $\beta$-blockers.

Previous studies investigated the effect of stress hormones (catecholamine and glucocorticoid) upon skin and monocyte in human and mouse. Chronic stress increases the number of monocyte in human. And in mice, chronic stress increases noradrenaline levels, and it causes the elevated hematopoietic stem cells proliferation and increased output of inflammatory monocyte (27). This work would suggest that catecholamine regulates monocyte number at the progenitor stem cell level. In the human study, administration of cortisol at a level equivalent to the level observed under stress, elevated the expression of chemotactic receptors in monocyte in skin blisters and increased the number of macrophages and neutrophils in skin blisters (28). These data suggest that glucocorticoid enhances the localization of monocytes to skin inflammatory sites. In the context of pressure ulcer healing, administration of propranolol reduced the migration of keratinocyte and macrophage, and consequently delayed wound healing suggesting that catecholamine is required for the reconstruction of skin tissue involving the migration of monocyte/macrophages (29). The role of adrenaline on cAMP-specific phosphodiesterase 4 (PDE4) activity in monocyte was investigated. In that study, adrenaline elevated PDE4 activity in cultured monocyte cells suggesting that catecholamine is involved in atopic dermatitis-specific modification of enzyme activity in monocyte (30). These data might suggest that downregulation of glucocorticoidinduced aromatase expression by catecholamine in human skin monocyte could occur like observed in this study using THP-1. If monocytes in human skin tissue respond to glucocorticoids and $\beta$-agonists in a similar manner to THP-1 cells in vitro, then a decline in the HPA (low glucocorticoid) and excitation of the SAM (high catecholamine) might have the effect of downregulating the secretion of estrogen in monocytes. This downregulation may cause a decrease in dermal elasticity and moisture, which would make skin tissues vulnerable and cause dermatitis (e.g. atopic dermatitis).

The results from these experiments use a single cell line (THP-1). Thus, confirmation using another human monocyte-derived cell line is required as well as from primary human skin monocytes. A co-culture system with other cells from skin tissue might provide a simple and powerful in vitro system to examine the role of monocytes in human skin tissue. Human monocyte-derived cell lines including THP-1 cells could be a component of this system as a model of infiltrated peripheral monocytes.

\section{Declaration of interest}

The authors declare that there is no conflict of interest that could be perceived as prejudicing the impartiality of the research reported.

\section{Funding}

This work was supported, in part, by a Grant-in-Aid from the Ministry of Education, Culture, Sports, Sciences and Technology of Japan (S O).

\section{Acknowledgements}

The authors are grateful to Dr Shizuo Nakajin for his scientific advises.

\section{References}

1 Sator PG, Schmidt JB, Rabe T \& Zouboulis CC. Skin aging and sex hormones in women - clinical perspectives for intervention by hormone replacement therapy. Experimental Dermatology 200413 (Supplement 4) 36-40. (doi:10.1111/j.1600-0625.2004.00259.x)

2 Creidi P, Faivre B, Agache P, Richard E, Haudiquet V \& Sauvanet JP. Effect of a conjugated oestrogen (premarin) cream on ageing facial

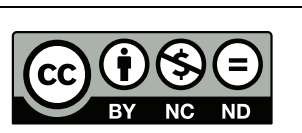

This work is licensed under a Creative Commons Attribution-NonCommercial-NoDerivatives 4.0 International License. 
skin. A comparative study with a placebo cream. Maturitas 199419 211-223. (doi:10.1016/0378-5122(94)90074-4)

3 Sator PG, Sator MO, Schmidt JB, Nahavandi H, Radakovic S, Huber JC $\&$ Honigsmann H. A prospective, randomized, double-blind, placebocontrolled study on the influence of a hormone replacement therapy on skin aging in postmenopausal women. Climacteric $2007 \mathbf{1 0}$ 320-334. (doi:10.1080/13697130701444073)

4 Santoro S, Santini M, Pepe C, Tognetti E, Cortelazzi C, Ficarelli E \& De Panfilis G. Aromatase inhibitor-induced skin adverse reactions: exemestane-related cutaneous vasculitis. Journal of the European Academy of Dermatology and Venereology 201125 596-598. (doi:10.1111/j.1468-3083.2010.03803.x)

5 Nelson LR \& Bulun SE. Estrogen production and action. Journal of the American Academy of Dermatology 200145 S116-S124. (doi:10.1067/ mjd.2001.117432)

6 Sawaya ME \& Penneys NS. Immunohistochemical distribution of aromatase and 3B-hydroxysteroid dehydrogenase in human hair follicle and sebaceous gland. Journal of Cutaneous Pathology 199219 309-314. (doi:10.1111/j.1600-0560.1992.tb01367.x)

7 Inoue T, Miki Y, Abe K, Hatori M, Hosaka M, Kariya Y, Kakuo S, Fujimura T, Hachiya A, Honma S, et al. Sex steroid synthesis in human skin in situ: the roles of aromatase and steroidogenic acute regulatory protein in the homeostasis of human skin. Molecular and Cellular Endocrinology 2012362 19-28. (doi:10.1016/j.mce.2012.05.005)

8 Emoto N, Ling N \& Baird A. Growth factor-mediated regulation of aromatase activity in human skin fibroblasts. Proceedings of the Society for Experimental Biology and Medicine 1991196 351-358. (doi:10.3181/00379727-196-43200)

9 Harada N. A unique aromatase (P-450AROM) mRNA formed by alternative use of tissue-specific exons 1 in human skin fibroblasts. Biochemical and Biophysical Research Communications 1992189 1001-1007. (doi:10.1016/0006-291X(92)92303-F)

10 Egawa M, Mukai K, Yoshikawa S, Iki M, Mukaida N, Kawano Y, Minegishi Y \& Karasuyama H. Inflammatory monocytes recruited to allergic skin acquire an anti-inflammatory M2 phenotype via basophil-derived interleukin-4. Immunity 201338 570-580. (doi:10.1016/j.immuni.2012.11.014)

11 Lea CK, Ebrahim H, Tennant S \& Flanagan AM. Aromatase cytochrome P450 transcripts are detected in fractured human bone but not in normal skeletal tissue. Bone 199721 433-440. (doi:10.1016/S8756-3282(97)00168-3)

12 Mor G, Yue W, Santen RJ, Gutierrez L, Eliza M, Berstein LM, Harada N, Wang J, Lysiak J, Diano S, et al. Macrophages, estrogen and the microenvironment of breast cancer. Journal of Steroid Biochemistry and Molecular Biology 199867 403-411. (doi:10.1016/S09600760(98)00143-5)

13 Tsuchiya S, Yamabe M, Yamaguchi Y, Kobayashi Y, Konno T \& Tada K. Establishment and characterization of a human acute monocytic leukemia cell line (THP-1). International Journal of Cancer 198026 171-176. (doi:10.1002/ijc.2910260208)

14 Chang KT, Lin HY, Kuo CH \& Hung CH. Tacrolimus suppresses atopic dermatitis-associated cytokines and chemokines in monocytes. Journal of Microbiology, Immunology and Infection 201649 409-416. (doi:10.1016/j.jmii.2014.07.006)

15 Lim YM, Moon SJ, An SS, Lee SJ, Kim SY, Chang IS, Park KL, Kim HA $\&$ Heo Y. Suitability of macrophage inflammatory protein-1beta production by THP-1 cells in differentiating skin sensitizers from irritant chemicals. Contact Dermatitis 200858 193-198. (doi:10.1111/ j.1600-0536.2007.01311.x)

16 Sekiguchi K, Koseki J, Tsuchiya K, Matsubara Y, Iizuka S, Imamura S, Matsumoto T, Watanabe J, Kaneko A, Aiba S, et al. Suppression of propionibacterium acnes-induced dermatitis by a traditional Japanese medicine, jumihaidokuto, modifying macrophage functions. EvidenceBased Complementary and Alternative Medicine 20152015 1-10. (doi:10.1155/2015/439258)

17 Shozu M, Zhao Y \& Simpson ER. Estrogen biosynthesis in THP1 cells is regulated by promoter switching of the aromatase (CYP19) gene. Endocrinology 1997138 5125-5135. (doi:10.1210/en.138.12.5125)

18 Buske-Kirschbaum A, Geiben A, Hollig H, Morschhauser E \& Hellhammer D. Altered responsiveness of the hypothalamuspituitary-adrenal axis and the sympathetic adrenomedullary system to stress in patients with atopic dermatitis. Journal of Clinical Endocrinology and Metabolism 200287 4245-4251. (doi:10.1210/ jc.2001-010872)

19 Watanabe M \& Nakajin S. Forskolin up-regulates aromatase (CYP19) activity and gene transcripts in the human adrenocortical carcinoma cell line H295R. Journal of Endocrinology 2004180 125-133. (doi:10.1677/joe.0.1800125)

20 Grisanti LA, Evanson J, Marchus E, Jorissen H, Woster AP, DeKrey W, Sauter ER, Combs CK \& Porter JE. Pro-inflammatory responses in human monocytes are b1-adrenergic receptor subtype dependent. Molecular Immunology 201047 1244-1254. (doi:10.1016/j.molimm.2009.12.013)

21 Bamias G, Evangelou K, Vergou T, Tsimaratou K, Kaltsas G, Antoniou C, Kotsinas A, Kim S, Gorgoulis V, Stratigos AJ, et al. Upregulation and nuclear localization of TNF-like cytokine 1A (TL1A) and its receptors DR3 and DcR3 in psoriatic skin lesions. Experimental Dermatology 201120 725-731. (doi:10.1111/j.16000625.2011.01304.x)

22 Jakob F, Homann D \& Adamski J. Expression and regulation of aromatase and 17 beta-hydroxysteroid dehydrogenase type 4 in human THP 1 leukemia cells. Journal of Steroid Biochemistry and Molecular Biology 199555 555-563. (doi:10.1016/0960-0760(95)00206-5)

23 Severn A, Rapson NT, Hunter CA \& Liew FY. Regulation of tumor necrosis factor production by adrenaline and beta-adrenergic agonists. Journal of Immunology 1992148 3441-3445.

24 Talmadge J, Scott R, Castelli P, Newman-Tarr T \& Lee J. Molecular pharmacology of the beta-adrenergic receptor on THP-1 cells. International Journal of Immunopharmacology 199315 219-228. (doi:10.1016/0192-0561(93)90098-J)

25 Watanabe M, Ohno S \& Nakajin S. Forskolin and dexamethasone synergistically induce aromatase (CYP19) expression in the human osteoblastic cell line SV-HFO. European Journal of Endocrinology 2005 152 619-624. (doi:10.1530/eje.1.01882)

26 Watanabe M, Noda M \& Nakajin S. Aromatase expression in a human osteoblastic cell line increases in response to prostaglandin $\mathrm{E}(2)$ in a dexamethasone-dependent fashion. Steroids 200772 686-692. (doi:10.1016/j.steroids.2007.05.006)

27 Heidt T, Sager HB, Courties G, Dutta P, Iwamoto Y, Zaltsman A, von Zur Muhlen C, Bode C, Fricchione GL, Denninger J, et al. Chronic variable stress activates hematopoietic stem cells. Nature Medicine 201420 754-758. (doi:10.1038/nm.3589)

28 Yeager MP, Pioli PA, Collins J, Barr F, Metzler S, Sites BD \& Guyre PM. Glucocorticoids enhance the in vivo migratory response of human monocytes. Brain, Behavior, and Immunity 201654 86-94. (doi:10.1016/j.bbi.2016.01.004)

29 Assis de Brito TL, Monte-Alto-Costa A \& Romana-Souza B. Propranolol impairs the closure of pressure ulcers in mice. Life Sciences 2014100 138-146. (doi:10.1016/j.lfs.2014.02.007)

30 Delgado M, Fernandez-Alfonso MS \& Fuentes A. Effect of adrenaline and glucocorticoids on monocyte cAMP-specific phosphodiesterase (PDE4) in a monocytic cell line. Archives for Dermatological Research 2002294 190-197. (doi:10.1007/s00403-002-0313-3)

Received in final form 13 January 2017

Accepted 26 January 2017

Accepted Preprint published online 26 January 2017 http://www.endocrineconnections.org

DOI: 10.1530/EC-16-0099 (c) 2017 The authors Published by Bioscientifica Ltd
This work is licensed under a Creative Commons Attribution-NonCommercial-NoDerivatives 4.0 International License. 